\title{
Effect of pregnancy planning and fertility treatment on cognitive outcomes in children at ages 3 and 5: longitudinal cohort study
}

\author{
C Carson researcher in statistics and epidemiology ${ }^{1}$, Y Kelly professor of lifecourse epidemiology ${ }^{23}$, \\ J J Kurinczuk director ${ }^{1}$, A Sacker research professor ${ }^{3}$, M Redshaw social scientist ${ }^{1}$, M A Quigley \\ reader in statistical epidemiology ${ }^{1}$
}

${ }^{1}$ National Perinatal Epidemiology Unit, University of Oxford, Headington, Oxford OX3 7LF, UK; ${ }^{2}$ Institute of Social and Economic Research, University of Essex, Colchester, Essex CO4 3SQ; ${ }^{3}$ Department of Epidemiology and Public Health, University College London, London WC1E 6BT

\begin{abstract}
Objective To investigate how pregnancy planning, time to conception, and infertility treatment influence cognitive development at ages 3 and 5.

Design Prospective population based cohort study.

Setting Millennium Cohort Study in the United Kingdom.

Participants 18818 children recruited at 9 months and followed up at 3 and 5 years. 11790 singletons with available data on pregnancy, cognitive outcomes, and confounders were included in analyses at age 3 and 12136 at age 5 .
\end{abstract}

Exposure measures Mothers reported whether the pregnancy was planned, and their feelings when first pregnant; those in whom the pregnancy was planned provided time to conception, and details of any assisted reproductive technologies. The population was divided into "unplanned" (unplanned and unhappy), "mistimed" (unplanned but happy), "planned" (planned, time to conception < 12 months), "subfertile" (planned, time to conception $\geq 12$ months), "induced ovulation" (received clomiphene citrate), and "assisted reproduction" (in vitro fertilisation or intracytoplasmic sperm injection). The "planned" group was the comparison group in all analyses.

Outcome measures Three components of the British Ability Scales (BAS II). Naming vocabulary assessed verbal ability at age 3; this test was repeated at age 5 with the picture similarities and pattern construction subscales, which measure non-verbal and spatial abilities.

Results In unadjusted analyses, the scores on all scales in children from unplanned pregnancies were significantly lower than in those from planned pregnancies-for example, the difference in mean verbal ability score at age 3 was -4.8 (95\% confidence interval -6.0 to $-3.7 ; \mathrm{P}<0.05)$, equivalent to an average delay of four months. After adjustment for sociodemographic factors these differences were attenuated: $-0.3(-1.3$ to 0.7$)$, equivalent to no delay. Children born after assisted reproduction performed consistently better in verbal ability tests $(3.8(-0.2$ to 7.9$)$ at age 3 and 3.5 (0.2 to 6.8 ) at age 5 ), which suggests that on average these children are three to four months ahead; this difference did not completely disappear with adjustment for confounders. Children born after infertility treatment had lower mean scores in non-verbal tests $(-1.2$ (-4.1 to 1.6) after assisted reproduction and -1.5 (-3.5 to 0.4$)$ after induced ovulation) and in spatial ability tests (-2.7 (-6.9 to 1.6) after assisted reproduction), though the differences were not significant.

Conclusions Pregnancy planning, subfertility, or assisted reproduction do not adversely affect children's cognitive development at age 3 or 5 . The differences observed in the unadjusted analyses are almost entirely explained by marked inequalities in socioeconomic circumstances between the groups.

\section{Introduction}

In the United Kingdom, as many as $30-40 \%$ of pregnancies that end in childbirth are unplanned. ${ }^{1-4}$ Meanwhile, the number of children born after assisted reproductive technologies is increasing annually. ${ }^{5}$ These scenarios illustrate the variation in pregnancy planning, desire for a child, and the ability to conceive that could be viewed together as part of a "conception continuum." At one extreme are those women whose pregnancy was an unwelcome surprise, through to those who consider the baby to be mistimed, to those who actively planned and conceived, and on to those who conceived only after a period of infertility or after assisted reproductive technology.

Children born after a prolonged time to conception or assisted reproduction, or both, are at greater risk of adverse health outcomes such as preterm birth, low birth weight, and congenital anomalies. ${ }^{78}$ In addition, some researchers have reported lower cognitive scores in children born after assisted reproduction. ${ }^{9-11}$ Unplanned pregnancies also have poorer perinatal outcomes, ${ }^{12}$ but there is little epidemiological research assessing whether children's development is associated with pregnancy intention. 
The effects of pregnancy planning, a parent's desire for a child, and fertility on cognitive outcomes might act through many pathways including biological differences, health related behaviours in pregnancy, ${ }^{13}{ }^{14}$ uptake of antenatal care, ${ }^{15}$ or parenting behaviours. A previous review highlighted the need for large scale population based studies with the capacity to examine possible causal pathways between pregnancy intention and markers of child development. ${ }^{16}$

We investigated the effects of pregnancy planning, time to conception, and fertility treatment on cognitive outcomes in the child up to the age of 5 using data from the Millennium Cohort Study.

\section{Methods \\ Millennium Cohort Study}

The Millennium Cohort Study is a nationally representative prospective cohort study of 18552 families across the UK. ${ }^{17} \mathrm{~A}$ random two stage sample of all infants born in 2000-2 and resident in the UK at 9 months was drawn from Department of Social Security Child Benefit Registers. The cohort study does not cover births where the infant died within the first 9-10 months after birth, but these constituted less than $1 \%$ of all births. ${ }^{18}$ Ethnically diverse and disadvantaged areas were oversampled to ensure adequate representation. ${ }^{19}$ Baseline interviews captured sociodemographic and health information, including questions about pregnancy and infertility treatment. Eighty per cent (14 898/18 552) and 79\% (14 678/18 552) of families completed the follow-up interviews when the children were aged 3 and 5 , respectively.

\section{Pregnancy planning, time to pregnancy, and infertility treatments}

Mothers were asked if they had planned to conceive and how they felt when they discovered they were pregnant. Those in whom the pregnancy was "planned" were then asked how long they took to conceive and if they had received fertility treatment. Women were grouped into the following categories:

- Unplanned (unplanned, unhappy about pregnancy)

- Mistimed (unplanned, happy about pregnancy)

- Planned (planned, time to conception $<12$ months)

- Subfertile (planned, time to conception $\geq 12$ months)

- Induced ovulation (planned, used drugs such as clomiphene citrate to induce ovulation)

- Assisted reproductive technologies (planned, used technologies such as in vitro fertilisation or intracytoplasmic sperm injection).

\section{Cognitive development measures}

Cognitive development was assessed with three subscales of the British Ability Scales, second edition (BAS II). At age 3 children completed the naming vocabulary component, which assessed verbal ability. This was repeated at age 5 together with the picture similarities and pattern construction components, which measure non-verbal and spatial abilities, respectively. ${ }^{20} 21$ The scales are adjusted for age (in three month bands) and indicate how a child's cognitive abilities have developed relative to his or her peers.

\section{Inclusion criteria, exclusions, and losses to follow-up}

The figure shows the number of children included in each analysis. Our analysis was restricted to singletons, for whom data on pregnancy was provided by their natural mother, and who were not conceived with donor gametes. Children who did not have adequate English language skills or had severe disabilities or behavioural problems did not complete the tests. Twenty four children had severe disabilities, 14 of whom had done the tests at age 3 ; to ensure consistency we excluded these children. In total, 18114 children were eligible for the study at age 9 months, of whom $14566(80 \%)$ responded to the survey at 3 years. At this time, 11790 (65\% of those eligible at 9 months) had completed the tests, provided data on confounding factors, and were included in the analysis. The analysis at aged 5 was not dependent on participation in the survey at age 3 . At this time, 14346 (79\% of those eligible at 9 months) children responded: 12136 (67\% of those eligible at 9 months) were included in the analysis of verbal abilities, 12176 (67\%) for non-verbal abilities, and 11206 (62\%) for spatial abilities.

\section{Statistical analysis}

We used linear regression to estimate the difference in mean ability score for each subscale across the pregnancy groups after adjustment for the child's sex, age, and other potential confounders and mediators. The "planned" group was the reference group in these analyses.

Adjustment was completed in stages because of the large number of potential confounders and mediators. Adjustment was made for the following variables:

A priori confounders or mediators (model 1)-Sex of child, age (in days), language spoken at home (English only, English plus another language).

Sociodemographic, health, and health related behaviours in pregnancy (model 2)-Maternal age, socioeconomic position (higher of mother or father using UK national statistics socioeconomic class, four categories); equivalised family income at baseline ${ }^{22}$; maternal qualifications (NVQ or equivalent groups); firstborn child; alcohol consumption in pregnancy (never, low, moderate, high ${ }^{23}$ ); smoking habits in pregnancy (non-smoker, gave up while pregnant, continued to smoke); mother's own health (such as asthma, diabetes, etc); family structure (married, cohabiting, or lone parent at appropriate sweep); father's age and qualifications (categorical variables that included a "no father" category for lone parent families).

Early life course (model 3)—Gestational age (in weeks); birth weight; breast feeding (none, less than four months, four months and more); maternal depression at 9 months (indicated by malaise inventory score ${ }^{24}$ ); Condon maternal postnatal attachment score. ${ }^{25}$

Later early life course (model 4)-Maternal and paternal depression (indicated by a Kessler score $\geq 9^{26}$ ); maternal and paternal parenting involvement scores (derived from reported frequency of reading, counting, learning alphabet, singing and drawing with the child, a higher score indicating greater involvement ${ }^{27}$ ); type of childcare (none, informal (other family, friends or au pair), formal (childminder or nursery)) and hours a week in childcare at appropriate sweep. The analysis at age 3 also included an indicator of positive parent-child relationship (based on the Pianta score ${ }^{28}{ }^{29}$ ).

At each stage variables were included if they were significantly associated with the outcome at a $5 \%$ level, after adjustment for 
other factors in the model. The results are reported as difference in mean score (regression coefficient) and converted into the equivalent of the progress one would expect over a month in a child of this age. Existing age equivalents derived for the cohort study population were used. For example, in a one month period, we would expect the test scores of a typical 5 year old to increase by 0.83 for naming vocabulary, 0.62 for picture similarities, and 1.81 for pattern construction. ${ }^{17} 30$

All analyses took the clustered stratified study design into account by using the survey commands in Stata version $10 .^{31}$ All reported estimates are weighted by sampling and non-response weights to account for missing data because of non-response at later sweeps. ${ }^{32}$

\section{Results \\ Descriptive characteristics of study population}

Forty one per cent (5149/12 136) of children were born after an unplanned pregnancy; $15 \%$ of mothers reported that they felt unhappy or ambivalent about the pregnancy ("unplanned" $\mathrm{n}=1822$ ), while $26 \%$ of mothers were happy ("mistimed" $n=3327)$. Fifty three per cent of mothers $(6244 / 12136)$ reported a planned pregnancy, conceived in less than 12 months ("planned group"); a further 4\% (480) conceived after 12 months or longer ("subfertile group"), while 1.4\% (167) had ovulation inducing drugs and 1\% (96) were born after assisted reproduction.

Table 1 describes the study population, indicating marked trends across the conception continuum. Table A on bmj.com provides further details. Babies conceived after assisted reproduction were, on average, born at an earlier gestation and lower birth weight than the children from other groups. We observed consistent patterns across the groups in terms of sociodemographic characteristics, timing of antenatal care, and health related behaviours in pregnancy. Compared with the planned fertile group the unplanned children were generally born to younger mothers, who were less likely to be in a stable relationship, had lower educational attainment, a lower family income, and a more disadvantaged socioeconomic position. Mothers in the unplanned groups were also more likely to smoke and drink heavily in pregnancy. The reverse was true for the mothers in the induced ovulation and assisted reproduction groups.

\section{Association between pregnancy planning and BAS scores}

Table 2 shows the results of the linear regression models exploring the effect of pregnancy planning, fertility, and infertility treatment on the separate BAS subscales. In unadjusted analyses, the "unplanned" children have lower scores than their planned counterparts. For example, the difference in verbal ability score at age 5 is $-4.6(-5.5$ to -3.6$)$, which equates to an average developmental delay of more than five months. After adjustment for sociodemographic factors these differences almost entirely disappear, and further adjustment for early and later life course factors has little effect (fully adjusted difference in mean score $-0.1(-1.0$ to 0.8$)$ or no delay).

\section{Association between subfertility, fertility treatment, and BAS scores}

The picture is less clear cut for the subfertile and fertility treatment groups, and the results differ across the BAS subscales. In unadjusted analyses, the children who were born after assisted reproduction had higher scores in the verbal ability tests than the planned children: $3.8(-0.2$ to 7.9$)$ and 3.5 (0.2 to 6.8 ) at ages 3 and 5, respectively. These differences suggest that they are on average three to four months ahead in development compared with the planned group. The differences were attenuated when we adjusted the models for confounding factors, particularly sociodemographic covariates: $1.6(-1.6$ to 4.7$)$ and $2.2(-0.6$ to 5.0$)$ at ages 3 and 5 , respectively.

Children born after infertility treatment seem to perform less well on the non-verbal tests, with adjusted difference in means of -1.2 ( -4.1 to 1.6$)$ and $-1.5(-3.5$ to 0.4$)$ for the assisted reproduction and induced ovulation groups, respectively, which is equivalent to more than two months' delay on average. Children born after assisted reproduction also have lower spatial ability scores: -2.7 ( -6.9 to 1.6$)$ or a 1.5 month delay. These results, however, are not significant. There is no evidence that subfertility has a strong effect on cognitive ability scores.

\section{Discussion}

\section{Summary of findings}

Children born after unplanned and mistimed pregnancies perform poorly in verbal ability tests at ages 3 and 5 compared with children born after a planned pregnancy, while children conceived after assisted reproduction perform better. After adjustment for confounders, particularly sociodemographic variables, however, these differences disappear for the unplanned and mistimed groups and are attenuated in the assisted reproduction group. There is some suggestion that children born after induced ovulation or assisted reproduction have lower non-verbal ability scores, and the assisted reproduction group also has lower spatial ability scores. Subfertility alone is not associated with cognitive test scores.

\section{Comparison with other studies}

Direct comparisons with other studies of children born after assisted reproduction and cognitive development are difficult because researchers have used a wide range of cognitive measures and have sampled different groups of children, and there is great variation in methodological quality. ${ }^{33} \mathrm{We}$ found that children born after assisted reproduction outperform their peers in verbal ability tests; a pattern that, though reduced, remains after adjustment for other factors. Yet these children seem to perform less well in the spatial and non-verbal tests. Previous studies have also identified delays in children born after assisted reproduction. ${ }^{9-11}{ }^{34}$ Other studies, generally those with a larger sample size, have found no evidence of an effect on overall ability. ${ }^{35-37} \mathrm{We}$ found no evidence of an adverse effect in the "subfertile" group, while Zhu et al described a modest increase in psychomotor delay with increasing time to conception among children aged 18 months. ${ }^{34}$ It could be that any effect seen at 18 months is no longer detectable at age 3 or 5 or that, in our population, prolonged time to conception per se had no adverse effects on cognitive outcome.

The epidemiological literature that examines the effects of pregnancy intention on cognitive outcomes in the child is sparse. Our findings are similar to those reported by Joyce et al, who found that unwanted or mistimed children in a large American cohort performed less well in maths, reading, and picture vocabulary tests, but that this was because of "family background and parental characteristics." ${ }^{38}$ Both studies found that the strength of pregnancy intention was important, with unplanned and unhappy groups achieving lower scores than the mistimed groups. 


\section{Potential mechanisms}

The influences on cognitive ability might be subtle, and it is plausible that the effects of pregnancy intention, fertility, and infertility treatment on verbal, non-verbal, and spatial skills vary. Children born after assisted reproduction (and to a lesser extent those born after induced ovulation and in the subfertile group) benefit from a generally advantageous socioeconomic position. The associated advantages, such as more highly educated parents or more parental involvement, might have the greatest effect on language skills, ${ }^{39} 40$ perhaps explaining some of the variation in the findings for the different aspects of cognition. At the other end of the spectrum, children born after mistimed or unplanned pregnancies might have access to fewer educational resources (such as books, puzzles, trips to library), which could mediate the association between pregnancy intention and cognitive outcome. ${ }^{41}$ Though our findings suggest that parenting behaviour has little additional effect once economic circumstances are accounted for, it is important to consider that the mechanism that drives these differences could act through parenting behaviours, maternal wellbeing, and the resources available in the family to facilitate experiential learning. ${ }^{29}$

\section{Strengths and limitations}

We used data from a large population based UK cohort, with sufficient power to allow an investigation of the full range of conception states rather than focusing on one group alone. In contrast with previous studies, data were available on many potential confounding and mediating factors. Our study, however, included only small numbers of children born after infertility treatments, so findings for these groups should be interpreted with caution. Unfortunately, the number of children born after specific forms of fertility treatment (such as intracytoplasmic sperm injection) was insufficient to allow separate analyses to be conducted. Missing data because of loss to follow-up can result in bias in cohort studies. We used non-response weights, which take into account factors associated with response, in the analysis to minimise the effects. ${ }^{19}$ The original protocol for the Millennium Cohort Study excluded from the cognitive tests children with severe behavioural problems and disabilities, children whose parent refused consent, and children who were too tired, ill, or overwhelmed to complete the tests. Unfortunately, it is not possible to separate out the reasons for missing test results. The proportion missing was small: $2.4-5.2 \%$ at age 3 and $0.3-1.8 \%$ at age 5 (table 2). We believe any adverse effect is unlikely to remove the large increase in cognitive scores observed in the unadjusted results for the assisted reproduction children. Reports of pregnancy intention could be problematic because women might later rationalise an unintended pregnancy as a wanted birth, though others have found recall to be reliable. ${ }^{42}$ Given that the proportion reporting an unplanned pregnancy is consistent with previous reports, we believe that the classification is reliable. ${ }^{14}$ Educational attainment and occupation reflect a complex nexus of influences including IQ, temperament, and opportunity. The links between these influences and pregnancy planning, however, are likely to be complex and driven by personal and social resources rather than cognitive ability, thus reducing the risk of residual confounding.

\section{Future research and implications}

Further work is needed to define "unplanned" and "unintended" pregnancy ${ }^{43} 44$ as it is an issue where labels are emotive for many parents. Research examining the specific pathways between pregnancy planning, parenting behaviours, and cognitive outcomes would add to our understanding. Work is needed to investigate whether there are real differences in verbal and non-verbal cognitive development in children born after assisted reproduction and, if so, why that might be the case.

\section{Conclusion}

In conclusion, we found no evidence that pregnancy planning, subfertility, or assisted reproduction per se adversely affect children's cognitive development at age 3 or 5 . Unadjusted analyses show that children born after unplanned pregnancy score poorly in cognitive tests compared with their planned counterparts, while children conceived after assisted reproduction do significantly better in tests of verbal ability. These differences are almost entirely explained by confounding by socioeconomic factors, providing further evidence of the influence of socioeconomic inequalities on the lives of children in the UK. To help children achieve their full potential, policy makers should continue to target social inequalities.

Contributors: All contributors participated in the design and the interpretation of the findings. CC analysed the data, drafted the manuscript, and is guarantor. All authors critically reviewed the manuscript and approved the final version.

Funding: This work was funded by a grant from the Medical Research Council.

Competing interests: All authors have completed the ICMJE uniform disclosure form at www.icmje.org/coi_disclosure.pdf (available on request from the corresponding author) and declare: no financial relationships with any organisations that might have an interest in the submitted work in the previous three years; no other relationships or activities that could appear to have influenced the submitted work.

Ethical approval: This research involved secondary analysis of the MCS and therefore did not require ethical approval. Ethical approval for the Millennium Cohort Study was granted from the multi-centre research ethics committee.

Data sharing: The datasets are available on the UK Data Archive. Further information about the study and data can be found at www.cls.ioe.ac. uk/.

1 Farrow A, Hull MGR, Northstone K, Taylor H, Ford WCL, Golding J. Prolonged use of oral contraception before a planned pregnancy is associated with a decreased risk of delayed conception. Hum Reprod 2002;17:2754-61.

2 Fleissig A. Unintended pregnancies and the use of contraception—changes from 1984 to 1989 . BMJ 1991;302:147.

3 Jayaweera $\mathrm{H}$, Joshi $\mathrm{H}$, Macfarlane $\mathrm{A}$, Hawkes D, Butler $\mathrm{N}$. Pregnancy and childbirth. In: Dex S, Joshi $\mathrm{H}$, eds. Children of the 21 st century: from birth to nine months. Policy Press, 2005:109-32.

4 Lakha F, Glasier A. Unintended pregnancy and use of emergency contraception among a large cohort of women attending for antenatal care or abortion in Scotland. Lancet 2006;368:1782-87.

5 Oakley L, Doyle P, Maconochie N. Lifetime prevalence of infertility and infertility treatment in the UK: results from a population-based survey of reproduction. Hum Reprod 2008;23:447-50.

6 Bachrach CA, Newcomer S. Intended pregnancies and unintended pregnancies: distinct categories or opposite ends of a continuum? Fam Plann Perspect 1999;31:251-2.

7 Helmerhorst FM, Perquin DA, Donker D, Keirse MJ. Perinatal outcome of singletons and twins after assisted conception: a systematic review of controlled studies. BMJ 2004;328:261.

8 Hansen M, Bower C, Milne E, de Klerk N, Kurinczuk JJ. Assisted reproductive technologies and the risk of birth defects-a systematic review. Hum Reprod 2005;20:328-38.

9 Bowen JR, Gibson FL, Leslie GI, Saunders DM. Medical and developmental outcome at 1 year for children conceived by intracytoplasmic sperm injection. Lancet 1998;351:1529-34.

10 Gibson FL, Ungerer JA, Leslie GI, Saunders DM, Tennant CC. Development, behaviour and temperament: a prospective study of infants conceived through in-vitro fertilization. Hum Reprod 1998;13:1727-32.

11 Knoester M, Helmerhorst FM, Vandenbroucke JP, van der Westerlaken LA, Walther FJ, Veen S. Cognitive development of singletons born after intracytoplasmic sperm injection compared with in vitro fertilization and natural conception. Fertil Steril 2008:90:289-96.

12 Kost K, Landry DJ, Darroch JE. The effects of pregnancy planning status on birth outcomes and infant care. Fam Plann Perspect 1998;30:223-30.

13 Hellerstedt WL, Pirie PL, Lando HA, Curry SJ, McBride CM, Grothaus LC, et al. Differences in preconceptional and prenatal behaviors in women with intended and unintended pregnancies. Am J Public Health 1998;88:663-6. 


\section{What is already known on this topic}

Children born after a prolonged time to conception and assisted reproduction are at greater risk of some adverse health outcomes, and some researchers have reported lower cognitive scores in such children

Unplanned pregnancies also have poorer perinatal outcomes, but there has been little epidemiological research to assess whether child development is associated with pregnancy planning

\section{What this study adds}

Unadjusted test scores at ages 3 and 5 indicate that children born after an unplanned pregnancy are four to five months behind planned children in verbal abilities, while children born after assisted reproduction are three to four months ahead

These findings are almost entirely because of differences in socioeconomic circumstances, highlighting the strong influence of social inequality on cognitive outcomes

14 Rosenberg KD, Gelow JM, Sandoval AP. Pregnancy intendedness and the use of periconceptional folic acid. Pediatrics 2003;111:1142-5.

15 D'Angelo DV, Gilbert BC, Rochat RW, Santelli JS, Herold JM. Differences between mistimed and unwanted pregnancies among women who have live births. Perspect Sex Reprod Health 2004;36:192-7.

16 Gipson JD, Koenig MA, Hindin MJ. The effects of unintended pregnancy on infant, child, and parental health: a review of the literature. Stud Fam Plann 2008;39:18-38.

17 Hansen K, ed. Millennium cohort study, first, second and third surveys: a guide to the datasets. 3rd ed. Centre for Longitudinal Studies, Institute of Education, University of London, 2008.

18 Office for National Statistics. Infant and perinatal mortality 2004: health areas, England and Wales. Office for National Statistics, 2004.

19 Plewis I. The Millennium cohort study: technical report on sampling. 4th ed. Centre for Longitudinal Studies, Bedford Group for Lifecourse and Statistical Studies, Institute of Education, University of London, 2007.

20 Elliott CD, Smith P, McCulloch K. British ability scales. 2nd ed (BAS II): technical manual. Ner Nelson, 1997.

21 Hill V. Through the past darkly: a review of the British ability scales second edition. Child Adolesc Ment Health 2005;10:87-98.

22 Ketende S, Joshi $\mathrm{H}$. Income and poverty. In: Hansen K, Joshi H, eds. Millennium cohor study, third survey: a user's guide to initial findings.Centre for Longitudinal Studies, Institute of Education, 2008.

23 Kelly Y, Sacker A, Gray R, Kelly J, Wolke D, Quigley MA. Light drinking in pregnancy, a risk for behavioural problems and cognitive deficits at 3 years of age? Int $J$ Epidemiol 2009;38:129-40.

24 Rutter M, Tizard J, Whitmore K. Education, health and behaviour. Longmans, 1970.

25 Condon JT, Corkindale C. The assessment of parent-to-infant attachment: development of a self report questionnaire instrument. J Reprod Infant Psychol 1998;16:57-76.

26 Wang PS, Simon GE, Avorn J, Azocar F, Ludman EJ, McCulloch J, et al. Telephone screening, outreach, and care management for depressed workers and impact on clinical and work productivity outcomes: a randomized controlled trial. JAMA 2007;298:1401-11.

27 Jones E. Parental relationships and parenting. In: Hansen K, Joshi H, Dex S, eds. Children of the 21st century: the first five years. Policy Press, 2010:53-73.

28 Pianta RC. Child-parent relationship scale (unpublished measure). University of Virginia, 1995.

29 Kiernan KE, Huerta MC. Economic deprivation, maternal depression, parenting and children's cognitive and emotional development in early childhood. Br J Socio 2008;59:783-806

30 Hansen $\mathrm{K}$, Joshi $\mathrm{H}$, eds. Millennium cohort study, third survey: a user's guide to the initia findings. Centre for Longitudinal Studies, Institute of Education, University of London, 2008 .
31 StataCorp. Stata statistical software: Release 10. StataCorp LP, 2007

32 Plewis I. Non-response in a birth cohort study: the case of the millennium cohort study. Int J Soc Res Methodol 2007:10:325-34.

33 Middelburg KJ, Heineman MJ, Bos AF, Hadders-Algra M. Neuromotor, cognitive, language and behavioural outcome in children born following IVF or ICSI-a systematic review. Hum Reprod Update 2008;14:219-31.

34 Zhu JL, Basso O, Obel C, Hvidtjorn D, Olsen J. Infertility, infertility treatment and psychomotor development: the Danish national birth cohort. Paediatr Perinat Epidemiol 2009:23:98-106.

35 Agarwal P, Loh SK, Lim SB, Sriram B, Daniel ML, Yeo SH, et al. Two-year neurodevelopmental outcome in children conceived by intracytoplasmic sperm injection: prospective cohort study. BJOG 2005;112:1376-83.

36 Ludwig AK, Sutcliffe AG, Diedrich K, Ludwig M. Post-neonatal health and development of children born after assisted reproduction: a systematic review of controlled studies. Eur J Obstet Gynecol Reprod Biol 2006;127:3-25.

37 Ponjaert-Kristoffersen I, Bonduelle M, Barnes J, Nekkebroeck J, Loft A, Wennerholm UB, et al. International collaborative study of intracytoplasmic sperm injection-conceived, in vitro fertilization-conceived, and naturally conceived 5 -year-old child outcomes: cognitive and motor assessments. Pediatrics 2005;115:e283-9.

38 Joyce TJ, Kaestner R, Korenman S. The effect of pregnancy intention on child development. Demography 2000;37:83-94.

39 Ermisch J. Origins of social immobility and inequality: parenting and early child development. Natl Inst Econ Rev 2008;205:62-71.

40 Lugo-Gil J, Tamis-LeMonda CS. Family resources and parenting quality: links to children's cognitive development across the first 3 years. Child Dev 2008;79:1065-85.

41 Baydar N. Consequences for children of their birth planning status. Fam Plann Perspect 1995;27:228-34,245

42 Joyce $\mathrm{T}$, Kaestner R, Korenman $\mathrm{S}$. On the validity of retrospective assessments of pregnancy intention. Demography 2002;39:199-213.

43 Barrett G, Wellings K. What is a "planned" pregnancy? Empirical data from a British study. Soc Sci Med 2002;55:545-57.

44 Earle S. "Planned" and "unplanned" pregnancy: deconstructing experiences of conception. Hum Fertil (Camb) 2004;7:39-42.

Accepted: 20 May 2011

Cite this as: $B M J 2011 ; 343: d 4473$ 


\section{Tables}

Table 1| Description of population at analysis at age $5(n=12136)$ in study of effect of pregnancy planning and fertility treatment on cognitive development in children. Figures are percentages unless otherwise specified

\begin{tabular}{|c|c|c|c|c|c|c|}
\hline & $\begin{array}{l}\text { Unplanned } \\
(n=1822,15 \%)\end{array}$ & $\begin{array}{c}\text { Mistimed } \\
(\mathrm{n}=3327,26 \%)\end{array}$ & $\begin{array}{c}\text { Planned }(\mathrm{n}=6244 \\
53 \%)\end{array}$ & $\begin{array}{l}\text { Subfertile } \\
(n=480,4 \%)\end{array}$ & $\begin{array}{l}\text { Induced ovulation } \\
\qquad(\mathrm{n}=167,1.4 \%)\end{array}$ & ART (n=96, 1\%) \\
\hline Male child & 51 & 50 & 51 & 48 & 49 & 47 \\
\hline Non-white & 13 & 14 & 10 & 10 & 4 & 13 \\
\hline Mean age (years) at 3 year questionnaire & 3.13 & 3.14 & 3.11 & 3.12 & 3.11 & 3.10 \\
\hline Mean age (years) at 5 year questionnaire & 5.21 & 5.21 & 5.20 & 5.21 & 5.19 & 5.15 \\
\hline \multicolumn{7}{|l|}{ Parents' characteristics } \\
\hline Family structure (married) & 32 & 48 & 77 & 80 & 84 & 90 \\
\hline Family structure (lone parent) & 36 & 19 & 4 & 3 & 2 & 2 \\
\hline Mean annual income at 9 months $(£)$ & 16040 & 17780 & 27250 & 27090 & 31550 & 30220 \\
\hline $\begin{array}{l}\text { Household social class (professional/ } \\
\text { managerial) }\end{array}$ & 26 & 36 & 58 & 57 & 66 & 66 \\
\hline Mean age of mother at birth of child (years) & 26.8 & 27.7 & 30.0 & 31.6 & 31.7 & 33.7 \\
\hline Mother's educational attainment (with degree) & 22 & 29 & 45 & 43 & 52 & 49 \\
\hline Cohort member is mother's first child & 36 & 45 & 40 & 52 & 61 & 70 \\
\hline Mother has ever suffered depression & 26 & 17 & 12 & 12 & 10 & 10 \\
\hline Father interviewed & 52 & 66 & 82 & 82 & 85 & 81 \\
\hline Mean age of father at birth of child (years) & 35.9 & 36.9 & 37.8 & 39.5 & 39.8 & 41.1 \\
\hline Father's educational attainment (with degree) ${ }^{*}$ & 27 & 32 & 46 & 44 & 49 & 53 \\
\hline \multicolumn{7}{|l|}{ Pregnancy related variables } \\
\hline $\begin{array}{l}\text { Mean gestation at pregnancy confirmation } \\
\text { (weeks) }\end{array}$ & 8.7 & 7.9 & 6.8 & 6.5 & 5.9 & 3.9 \\
\hline $\begin{array}{l}\text { Mean gestation at received antenatal care } \\
\text { (weeks) }\end{array}$ & 13.3 & 12.8 & 11.4 & 11.3 & 10.0 & 10.1 \\
\hline Continued to smoke in pregnancy & 37 & 27 & 13 & 18 & 12 & 5 \\
\hline Moderate/high alcohol intake in pregnancy & 11 & 7 & 7 & 7 & 7 & 2 \\
\hline Mean gestational age (weeks) & 39.1 & 39.1 & 39.3 & 39.2 & 39.0 & 38.4 \\
\hline Mean birth weight $(\mathrm{g})$ & 3330 & 3340 & 3430 & 3320 & 3310 & 3200 \\
\hline Breast feeding (\% breast fed at all) & 58 & 70 & 79 & 80 & 82 & 88 \\
\hline \multicolumn{7}{|l|}{ Parenting variables } \\
\hline Weak postnatal attachment at 9 months $\dagger$ & 28 & 20 & 24 & 23 & 19 & 21 \\
\hline $\begin{array}{l}\text { Mother's positive relationship with child at age } \\
3 \text { (mean) }\end{array}$ & 33.0 & 33.5 & 33.8 & 33.9 & 34.0 & 33.6 \\
\hline $\begin{array}{l}\text { Mother's involvement score at } 5 \text { years } \\
\text { (mean) } \neq\end{array}$ & 16.2 & 16.8 & 16.8 & 16.9 & 17.4 & 17.3 \\
\hline Father's high involvement score at 5 years $\ddagger$ & 34 & 33 & 33 & 32 & 38 & 36 \\
\hline \multicolumn{7}{|l|}{ Childcare and schooling } \\
\hline Start childcare aged $<1$ year & 54 & 54 & 61 & 59 & 71 & 58 \\
\hline Mean hours/week in childcare at age 3 & 12.5 & 13.2 & 15.0 & 14.3 & 16.5 & 14.6 \\
\hline Formal childcare at age 3 & 22 & 22 & 31 & 29 & 39 & 35 \\
\hline Mean hours/week in childcare at age 5 & 8.2 & 7.0 & 5.6 & 5.2 & 5.2 & 5.7 \\
\hline Formal childcare at age 5 & 4 & 4 & 6 & 4 & 6 & 4 \\
\hline At school full time at age 5 & 97 & 97 & 97 & 97 & 98 & 99 \\
\hline \multicolumn{7}{|l|}{ British Ability Scale II } \\
\hline Mean verbal ability score at age 3 & 71.8 & 73.8 & 76.4 & 77.6 & 77.4 & 81.3 \\
\hline Mean verbal ability score at age 5 & 105.9 & 107.1 & 110.5 & 112.0 & 115.0 & 114.0 \\
\hline Mean non-verbal ability score at age 5 & 81.1 & 81.2 & 83.1 & 82.7 & 81.9 & 82.5 \\
\hline Mean spatial ability score at age 5 & 85.9 & 86.9 & 90.0 & 90.4 & 90.6 & 86.1 \\
\hline
\end{tabular}


Table 1 (continued)

$\begin{array}{ccccc}\text { Unplanned } & \text { Mistimed } & \text { Planned }(n=6244, & \text { Subfertile } & \text { Induced ovulation } \\ (n=1822,15 \%) & (n=3327,26 \%) & 53 \%) & (n=480,4 \%) & (n=167,1.4 \%)\end{array}$ ART $(n=96,1 \%)$

$\mathrm{ART}=$ assisted reproductive techniques.

*\% shown is \% among fathers who responded $(\mathrm{n}=8905)$.

†Score in lowest $25 \%$ of population is considered clinically relevant. ${ }^{25}$

¥Mother's score treated as continuous variable and mean score reported. Father's score is categorised as low/medium/high so that non-responders and missing can be included. 
Table 2/ Difference in mean (95\% confidence interval) scores on British Ability Scales (BAS) with accumulating additional adjustment in study of effect of pregnancy planning and fertility treatment on cognitive development in children

\begin{tabular}{|c|c|c|c|c|c|c|}
\hline Model & $\begin{array}{c}\text { Unplanned }(n=1822 \\
15 \%)\end{array}$ & $\begin{array}{c}\text { Mistimed }(\mathrm{n}=3327 \\
26 \%)\end{array}$ & $\begin{array}{c}\text { Planned } \\
(n=6224,53 \%)\end{array}$ & Subfertile $(480,4 \%)$ & $\begin{array}{l}\text { Induced ovulation } \\
\quad(n=167,1.4 \%)\end{array}$ & ART $(n=96,1 \%)$ \\
\hline \multicolumn{7}{|c|}{ Verbal abilities at age $3(n=11790)^{*}$} \\
\hline$\%$ missing data† & 4.5 & 52 & 3.5 & 3.4 & 2.4 & 4.0 \\
\hline Unadjusted model & $-4.8 \ddagger(-6.0$ to -3.7$)$ & $-2.4 \ddagger(-3.4$ to -1.5$)$ & \multirow[t]{5}{*}{ Reference } & $1.1(-0.7$ to 2.9$)$ & $0.2(-2.8$ to 3.1$)$ & $3.8(-0.2$ to 7.9$)$ \\
\hline Plus a priori confounders§ & $-5.3 \ddagger(-6.4$ to -4.3$)$ & $-2.8 \neq(-3.7$ to 2.0$)$ & & $0.7(-1.0$ to 2.5$)$ & $-0.3(-3.2$ to 2.5$)$ & $4.1 \ddagger(0.8$ to 7.5$)$ \\
\hline $\begin{array}{l}\text { Plus sociodemographic } \\
\text { factors }\end{array}$ & $-0.9(-1.9$ to 0.2$)$ & $-0.4(-1.2$ to 0.4$)$ & & $0.3(-1.5$ to 2.1$)$ & $-2.3(-5.0$ to 0.5$)$ & $1.2(-2.0$ to 4.4$)$ \\
\hline $\begin{array}{l}\text { Plus early life course } \\
\text { factors }\end{array}$ & $-0.8(-1.8$ to 0.3$)$ & $-0.3(-1.1$ to 0.5$)$ & & $0.4(-1.3$ to 2.2$)$ & $-2.0(-4.7$ to 0.7$)$ & $1.7(-1.5$ to 4.9$)$ \\
\hline $\begin{array}{l}\text { Plus later life course } \\
\text { factors }\end{array}$ & $-0.3(-1.3$ to 0.7$)$ & $-0.2(-1.0$ to 0.5$)$ & & $0.3(-1.5$ to 2.0$)$ & $-2.4(-5.0$ to 0.2$)$ & $1.6(-1.6$ to 4.7$)$ \\
\hline \multicolumn{7}{|c|}{ Verbal abilities at age $5(n=12136) \uparrow$} \\
\hline$\%$ missing data & 1.7 & 1.0 & 1.1 & 0.6 & 1.0 & 1.2 \\
\hline Unadjusted model & $-4.6 \neq(-5.5$ to -3.6$)$ & $-3.4 \ddagger(-4.2$ to -2.5$)$ & \multirow[t]{5}{*}{ Reference } & $1.5 \ddagger(0.1$ to 3.0$)$ & $4.5 \ddagger(2.2$ to 6.8$)$ & $3.5 \ddagger(0.2$ to 6.8$)$ \\
\hline Plus a priori confounders§ & $-4.9 \ddagger(-5.8$ to -4.0$)$ & $-2.9 \ddagger(-3.7$ to -2.2$)$ & & $1.4(0.0$ to 2.8$)$ & $4.0 \ddagger(1.7$ to 6.3$)$ & $4.8(2.1$ to 7.4$)$ \\
\hline $\begin{array}{l}\text { Plus sociodemographic } \\
\text { factors }\end{array}$ & $-0.2(-1.2$ to 0.7$)$ & $-0.2(-0.9$ to 0.6$)$ & & $1.0(-0.4$ to 2.4$)$ & $2.0 \ddagger(-0.1$ to 4.2$)$ & $2.0(-0.7$ to 4.8$)$ \\
\hline $\begin{array}{l}\text { Plus early life course } \\
\text { factors }\end{array}$ & $-0.2(-1.1$ to 0.7$)$ & $-0.2(-0.9$ to 0.5$)$ & & $1.2(-0.2$ to 2.6$)$ & $2.2 \ddagger(0.1$ to 4.3$)$ & $2.3(-0.5$ to 5.1$)$ \\
\hline $\begin{array}{l}\text { Plus later life course } \\
\text { factors }\end{array}$ & $-0.1(-1.0$ to 0.8$)$ & $-0.2(-0.9$ to 0.5$)$ & & $1.1(-0.3$ to 2.5$)$ & $2.1(0.0$ to 4.2$)$ & $2.2(-0.6$ to 5.0$)$ \\
\hline \multicolumn{7}{|c|}{ Non-verbal abilities at age $5(n=12176)^{\star *}$} \\
\hline$\%$ missing data $\dagger$ & 1.4 & 1.0 & 0.9 & 0.6 & 1.0 & 0.3 \\
\hline Unadjusted model & $-1.9 \ddagger(-2.7$ to -1.1$)$ & $-1.8 \ddagger(-2.4$ to -1.6$)$ & \multirow[t]{5}{*}{ Reference } & $-0.1(-1.2$ to 1.1$)$ & $-1.1(-3.1$ to 0.9$)$ & $-1.2(-4.1$ to 1.8$)$ \\
\hline Plus a priori confounders§ & $-2.0 \ddagger(-2.8$ to -1.2$)$ & $-1.8 \ddagger(-2.4$ to -1.2$)$ & & $-0.2(-1.3$ to 1.0$)$ & $-1.1(-3.1$ to 0.9$)$ & $-0.8(-3.7$ to 2.1$)$ \\
\hline $\begin{array}{l}\text { Plus sociodemographic } \\
\text { factors }\end{array}$ & $-0.3(-1.1$ to 0.5$)$ & $-0.6 \neq(-1.2$ to 0.0$)$ & & $0.0(-1.2$ to 1.1$)$ & $-1.6(-3.6$ to 0.3$)$ & $-1.4(-4.2$ to 1.5$)$ \\
\hline $\begin{array}{l}\text { Plus early life course } \\
\text { factors }\end{array}$ & $-0.2(-1.0$ to 0.6$)$ & $-0.6(-1.2$ to 0.0$)$ & & $0.1(-1.1$ to 1.2$)$ & $-1.5(-3.5$ to 0.4$)$ & $-1.2(-4.1$ to 1.6$)$ \\
\hline $\begin{array}{l}\text { Plus later life course } \\
\text { factors }\end{array}$ & $-0.2(-1.0$ to 0.6$)$ & $-0.6(-1.2$ to 0.0$)$ & & $0.1(-0.1$ to 1.2$)$ & $-1.5(-3.5$ to 0.4$)$ & $-1.2(-4.1$ to 1.6$)$ \\
\hline \multicolumn{7}{|c|}{ Spatial abilities at age $5(n=11206)+\dagger$} \\
\hline$\%$ missing data† & 1.8 & 1.3 & 1.2 & 0.6 & 1.0 & 0.3 \\
\hline Unadjusted model & $-4.5 \ddagger(-5.8$ to -3.1$)$ & $-2.7 \ddagger(-3.7$ to -1.8$)$ & \multirow[t]{5}{*}{ Reference } & $0.5(-1.4$ to 2.3$)$ & $0.7(-2.9$ to 4.3$)$ & $-3.3(-7.9$ to 1.3$)$ \\
\hline Plus a priori confounders§ & $-4.7 \ddagger(-6.0$ to -3.3$)$ & $-2.9 \ddagger(-3.9$ to -2.0$)$ & & $0.2(-1.6$ to 2.0$)$ & $0.5(-2.9$ to 4.0$)$ & $-2.7(-7.1$ to 1.7$)$ \\
\hline $\begin{array}{l}\text { Plus sociodemographic } \\
\text { factors }\end{array}$ & $-1.0(-2.3$ to 0.3$)$ & $-0.7(-1.6$ to 0.2$)$ & & $0.6(-1.1$ to 2.4$)$ & $-0.2(-3.7$ to 3.3$)$ & $-3.2(-7.3$ to 1.0$)$ \\
\hline $\begin{array}{l}\text { Plus early life course } \\
\text { factors }\end{array}$ & $-0.9(-2.2$ to 0.4$)$ & $-0.6(-1.5$ to 0.3$)$ & & $1.0(-0.8$ to 2.7$)$ & $0.2(-3.2$ to 3.5$)$ & $-2.5(-6.7$ to 1.8$)$ \\
\hline $\begin{array}{l}\text { Plus later life course } \\
\text { factors }\end{array}$ & $-0.8(-2.1$ to 0.5$)$ & $-0.6(-1.6$ to 0.3$)$ & & $0.9(-0.9$ to 2.7$)$ & $0.0(-3.4$ to 3.3$)$ & $-2.7(-6.9$ to 1.6$)$ \\
\hline
\end{tabular}

*Additional adjustments: sociodemographic—maternal age, social class, income, qualifications, first born; early life course—birth weight, breast feeding; later life course-maternal positive relationship score, maternal involvement score, age started childcare.

$\dagger \%$ of children eligible for inclusion in analysis who do not have BAS score. \% weighted for design effects only, not for non-response.

$\ddagger \mathrm{P}<0.05$ (significant).

$\S A$ priori confounders were age at sweep, language (English only, English and another), sex of cohort member.

TAdditional adjustments: sociodemographic_-maternal age, social class, income, family structure, qualifications, first born, alcohol in pregnancy, smoking in pregnancy, father's qualifications; early life course—birth weight, breast feeding; later life course—maternal involvement.

${ }^{* \star A}$ Additional adjustments: sociodemographic—social class, income, qualifications, father's age, father's qualifications; early life course—-birth weight, breast feeding; later life course-maternal involvement, childcare (any, informal, formal).

††Additional adjustments: sociodemographic—social class, income, qualifications, alcohol in pregnancy, father's qualifications; early life course-gestation, birth weight, breast feeding; later life course—-maternal involvement, maternal discipline, schooling (full time, part time). 


\section{Figure}

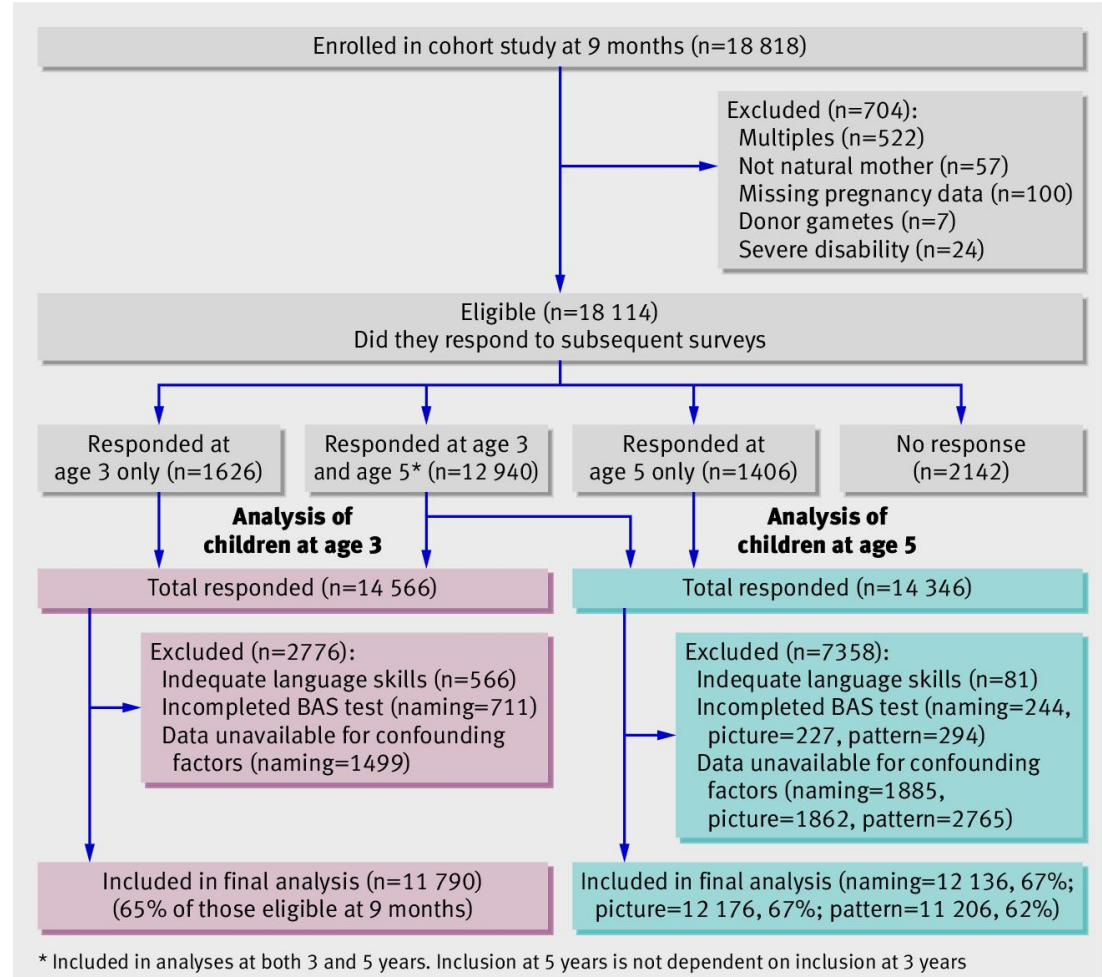

Flow of participants though study of pregnancy planning on cognitive outcomes in child, showing numbers available for analyses at ages 3 and 5. Naming=naming vocabulary (verbal ability). Picture=picture similarities (non-verbal ability). Pattern=pattern construction (spatial ability) 